\title{
Structural Characterization of High Entropy Alloy (FeCoCrNiCu) Synthesized by Mechanical Alloying
}

Cintya Arroyo ${ }^{1}$, Luis Bejar Gómez ${ }^{2}$, Claudio Aguilar ${ }^{3}$ and Ismeli Alfonso ${ }^{4}$

${ }^{1}$ Universidad Michoacana de San Nicolás de Hidalgo, Morelia, Michoacan de Ocampo, Mexico,

${ }^{2}$ Universidad Michoacana de San Nicolás de Hidalgo, Michoacan de Ocampo, Mexico, ${ }^{3}$ Universidad

Técnica Federico Santa Maria, Valparaíso, Valparaiso, Chile, ${ }^{4}$ Universidad Nacional Autónoma de México, Morelia, Michoacan de Ocampo, Mexico

High entropy alloys (HEAs) which usually contain five or more elements with equal or near equal atomic ratios, were proposed recently at the start of this century [1,2]. It opens up the possibility of creating new metallic alloys with good mechanical properties, especially at elevated temperatures. In these alloys, the entropy term may dominate over enthalpy, preventing the occurrence of chemical ordering [3,4]. Mechanical alloying (MA) process is described by the repeated welding and fracturing of powder particles entrapped between milling media, the extent of which depends on the mechanical attributes of powder constituents. MA offers the advantage of extended solid solubility even in immiscible systems. It can be attributed to the enhanced diffusion rates due to nanosize of powder components before alloying. Therefore, besides increased configurational entropy, MA lends enhanced stability to solid solution phases in HEAs [5].

In this work, the FeCoCrNiCu-HEA was synthesized during $100 \mathrm{~h}$ by mechanical alloying. The pure elements were alloyed in a planetary mill, at $300 \mathrm{rpm}$ with a ball / powder ratio of 10: 1 and a ball / ball ratio of 1: 1 . The alloyed powders were sintered in a high temperature tube furnace at $1100^{\circ} \mathrm{C}$ for $2 \mathrm{~h}$. The microstructural characterization of HEA bulk was carried out by X-ray diffraction to identify the phases formed after sintering. Also, the bulk was analyzed by scaning electron microscopy (SEM) and energy dispersive spectroscopy (EDS) to determine the morphology and chemical composition of the phases formed.

Figure 1 shows the diffraction pattern of HEA after sintering, in which the presence of two phases are appreciated. These phases are FCC and FCC with $\mathrm{Cu}$ precipitations, the formation of precipitations are attributed to the strong repulsive interaction of $\mathrm{Cu}$ with the other elements, and that $\mathrm{Cu}$ has the highest positive enthalpy of mixing with $\mathrm{Fe}, \mathrm{Cr}, \mathrm{Co}$ and $\mathrm{Ni}$ [6].

Figure 2a shows Backscattered electron image (BSE), in which the two phases formed can be observed, Fo is the dark phase and $\mathrm{Fc}$ is the light phase, also the presence of porosity. Figure $2 \mathrm{~b}$ shows the EDS chemical mapping of HEA, where it is observed that the elements of the alloy are uniformly distributed except for $\mathrm{Cu}$ that precipitates in certain areas. These precipitations coincide with the diffraction pratrons obtained in figure 1 .

In conclusion, the microstructure of $\mathrm{FeCoCrNiCu} \mathrm{HEA}$ sintered at $1100^{\circ} \mathrm{C}$ for $2 \mathrm{~h}$, is composed of two phases, these phases are FCC, one of them with $\mathrm{Cu}$ precipitate. 


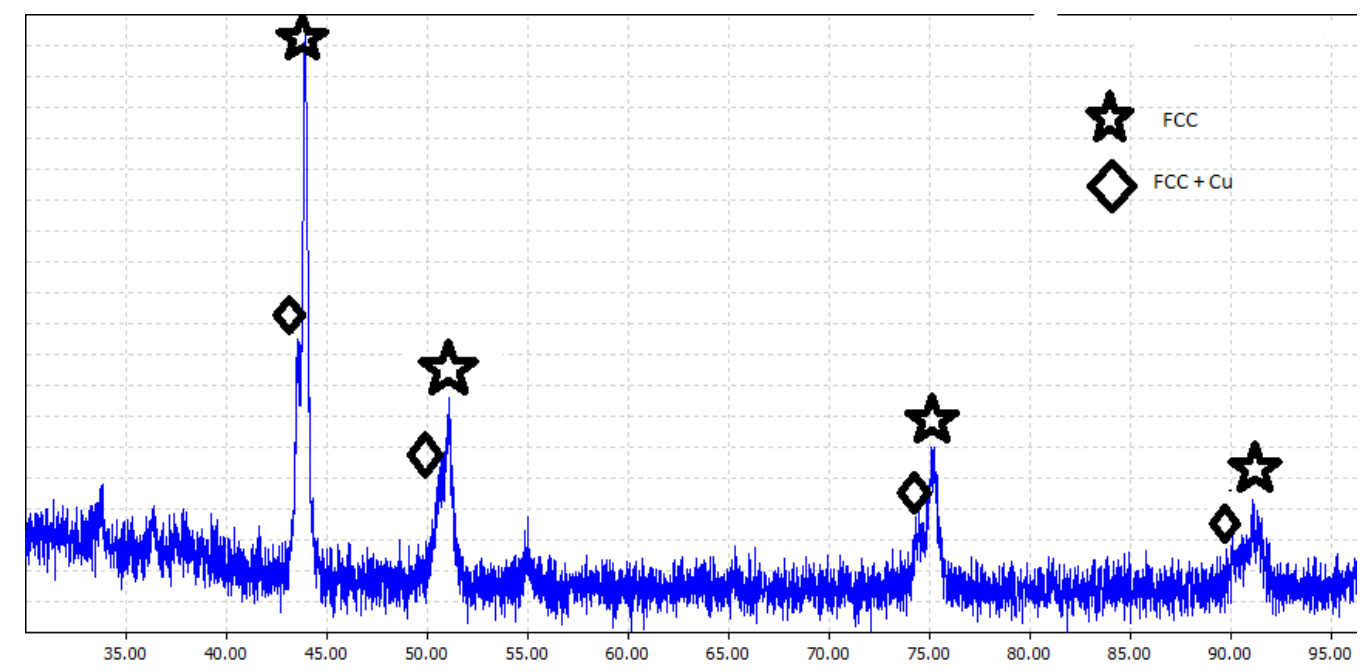

Figure 1. Diffraction pattern of $\mathrm{FeCoCrNiCu} \mathrm{HEA}$.

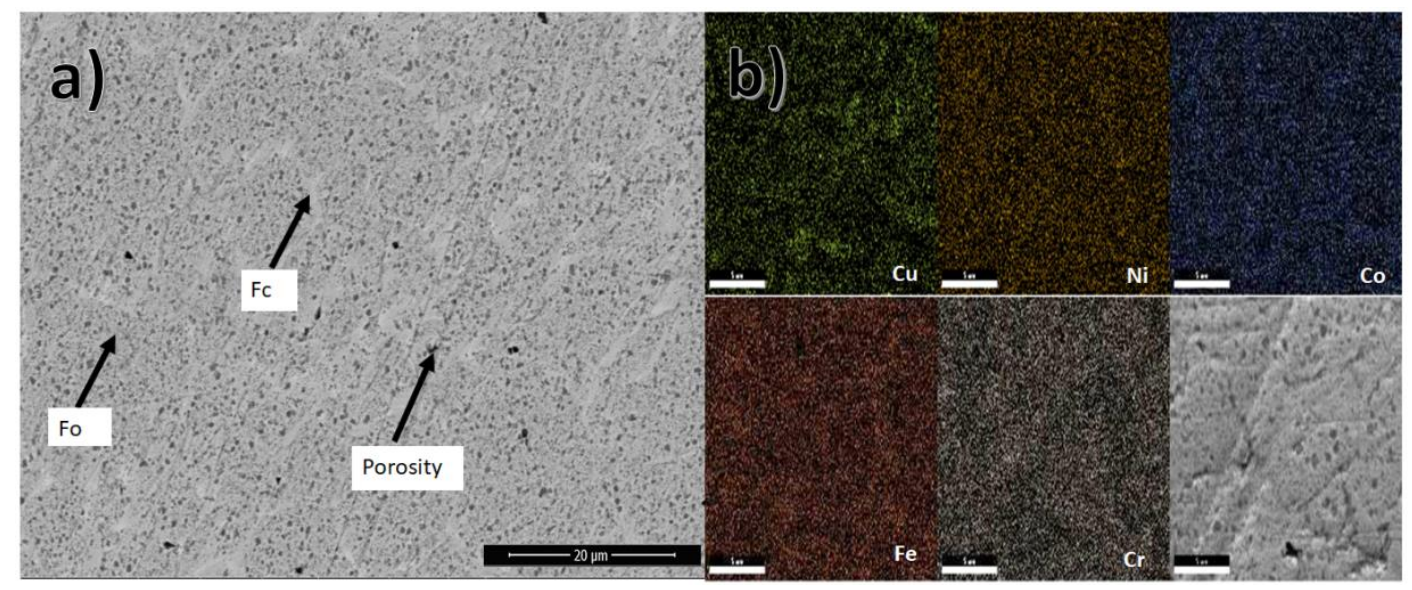

Figure 2. SEM images of FeCoCrNiCu HEA, a) BSE image and b) EDS chemical mapping.

\section{References}

[1] A. Y. Churyumov, A. V. Pozdniakov, A. I. Bazlov, H. Mao, V. I. Polkin, and D. V. LouzguineLuzgin, "Effect of $\mathrm{Nb}$ Addition on Microstructure and Thermal and Mechanical Properties of Fe-Co-Ni$\mathrm{Cu}-\mathrm{Cr}$ Multiprincipal-Element (High-Entropy) Alloys in As-Cast and Heat-Treated State," Jom, vol. 71, no. 10, pp. 3481-3489, 2019.

[2] Y. Xueqian, L. Guizhong, B. Yufeng, D. Xintao, and G. Jingjie, "Influence of gradual replacement of aluminum for copper in FeCrCoNiCu alloys," Materwiss. Werksttech., vol. 49, no. 11, pp. 13731380, 2018.

[3] Y. Zhang, Y.J. Zhou, J.P. Lin, G.L. Chen, and P.K. Liaw, Adv. Eng. Mater. 10, 534 (2008).

[4] D.B. Miracle and O.N. Senkov, Acta Mater. 122, 448 (2017).

[5] M. Vaidya, G. M. Muralikrishna, and B. S. Murty, "High-entropy alloys by mechanical alloying: A review," J. Mater. Res., vol. 34, no. 5, pp. 664-686, 2019.

[6] S. Praveen, B. S. Murty, and R. S. Kottada, "Alloying behavior in multi-component AlCoCrCuFe and NiCoCrCuFe high entropy alloys,” Mater. Sci. Eng. A, vol. 534, pp. 83-89, 2012. 